\section{REFERENCES}

1. U. Balachandran, S. L. Morissette, J. T. Dusek, R. L. Mieville, R. B. Poeppel, M. S. Kleefisch, S. Pei, T. P. Kobylinski, and C. A. Udovich, in Proceedings of the Coal Liquefaction and Gas Conversion Contractors Review Conference, Vol. 1, U.S. Dept. of Energy, Pittsburgh Energy Technology Center, pp. 138-160, (1993).

2. T. J. Mazanec, T. L. Cable, and J. G. Jr. Frye, Solid State Ionics, 111, 53 (1992)

3. U. Balachandran, J. T. Dusek, S. M. Sweeney, R. L. Mieville, P. S. Maiya, M. S. Kleefisch, S. Pei, T. P. Kobylinski, and A. C. Bose, in Proceedings of the 3rd International Conference on Inorganic Membranes, Y. H. Ma, Editor, p. 229, Sponsored by North American Membrane Society; AIChE Separations Division, and American Filterations Society (1994).

4. S. Pei, M. S. Kleefisch, T. P. Kobylinski, J. Faber, C. A. Udovich, V. Zhang-McCoy, B. Dabrowski, U. Balachandran, R. L. Mieville, and R. B. Poeppel, Catal. Lett., 30, 201 (1995).

5. U. Balachandran, J. T. Dusek, S. M. Sweeney, R. B. Poeppel, R. L. Mieville, P. S. Maiya, M. S. Kleefisch, S. Pei, T. P. Kobylinski, C. A. Udovich, and A. C. Bose, Am. Ceram. Soc. Bull, 74, 71 (1995).

6. T. L. Cable, European Pat. EP 0438902 A2 (1991).

7. H. U. Anderson, C. C. Chen, L. W. Tai, and M. M.
Nasrallah, in Ionic and Mixed Conduction Ceramics, T. A. Ramanarayaman, W. L. Worrell, and H. L. Tuller, Editors, PV 94-7, p. 376, The Electrochemical Society Proceedings Series, Pennington, NJ (1994).

8. F. A. Kroger, The Chemistry of Imperfect Crystals, North-Holland Publishing Co., Amsterdam (1964).

9. G. Brouwer, Philips Res. Rep., 9, 366 (1954).

10. H. L. Tuller, in Nonstoichiometric Oxides, $\mathrm{O}, \mathrm{T}$. Sorensen, Editor, p. 271, Materials Science Series, Academic Press, New York (1981).

11. J.-H. Park, Physica B, 150, 80 (1988)

12. D. Yuan and F. A. Kroger, This Journal, 116, 594 (1969).

13. H. Rickert, Electrochemistry of Solids, p. 99, SpringerVerlag, New York (1982).

14. B. Ma, J.-H. Park, C. U. Segre, and U. Balachandran, Mater. Res. Soc. Symp. Proc., 393, 49 (1995).

15. T. Ishigaki, S. Yamauchi, K. Kishio, J. Mizusaki, and K. Fueki, J. Solid State Chem., 73, 179 (1988)

16. K. Nisancioglu and T. M. Gur, Solid State Ionics, 72, 199 (1994)

17. B. Ma, U. Balachandran, J.-H. Park, and C. U. Segre, ibid., 83, 65 (1996)

18. B. Ma, U. Balachandran, C.-C. Chao, J.-H. Park, and C. U. Segre, in Proceedings of MRS Fall Meeting, Boston, MA, Nov. 27-Dec. 1, 1995.

19. H. Kruidhof, H. J. M. Bouwmeester, R. H. E. Doorn, and A. J. Burggraf, Solid State Ionics, 63, 816 (1993).

\title{
Surface Morphology of p-Type (100) Silicon Etched in Aqueous Alkaline Solution
}

\author{
P. M. M. C. Bressers and J. J. Kelly* \\ Debye Institute, Department of Condensed Matter, Utrecht University, 3508 TA Utrecht, The Netherlands
}

\author{
J. G. E. Gardeniers and M. Elwenspoek
}

MESA-Research Institute, University of Twente, 7500 AE Enschede, The Netherlands

\section{ABSTRACT}

We report on a study of the morphology of (100) silicon surfaces etched in aqueous alkaline solutions. It is shown that the formation of pyramidal hillocks during etching can be influenced in two different ways: by the presence of an oxidizing agent (ferricyanide or oxygen) in the etchant solution, or by etching under anodic bias. In both cases pyramid formation is suppressed without a significant change of the etch rate. The addition of ferricyanide does not markedly change the etching anisotropy. The formation, stability, and suppression of the pyramids are discussed.

\section{Introduction}

Anisotropic wet chemical etching is an important step in the fabrication of micromechanical devices. Of the anisotropic etchants, aqueous $\mathrm{KOH}$ solutions are most commonly used for $\mathrm{Si}$. The etch rate of (111)Si is a factor of at least 100 smaller than that of the other orientations. ${ }^{1,2}$ The large anisotropy makes it possible to etch structures such as V-grooves in (100)Si wafers. ${ }^{3}$ Unfortunately, a maximum in the etch rate for $4.0 \mathrm{M} \mathrm{KOH}$ is accompanied by an extremely rough surface. ${ }^{2}$ Several groups ${ }^{2-6}$ report that this roughness is due to the formation of pyramidal hillocks during etching. Since for many applications smooth surfaces are of the utmost importance, these defects can cause serious problems. ${ }^{7}$ In micromachining, pyramid formation is avoided by etching at increased $\mathrm{KOH}$ concentration. ${ }^{2,8}$ The improved surface morphology, however, is achieved at the expense of the etch rate which decreases with increasing $\mathrm{KOH}$ concentration above $4.0 \mathrm{M}$. ${ }^{2}$ To raise the etch rate, a higher temperature is required. With $\mathrm{SiO}_{2}$ as a masking material the combination of high $\mathrm{KOH}$ concentration and higher temperature constitutes a problem for the chemical stability of the mask.

In this paper we describe a study of the surface morphology of Si etched in $4.0 \mathrm{M} \mathrm{KOH}$ solutions at $70^{\circ} \mathrm{C}$. It is

\footnotetext{
* Electrochemical Society Active Member
}

shown how hillock formation can be suppressed without drastically changing the etch rate or the etching anisotropy. The results suggest that it should be possible to obtain a more acceptable compromise with respect to the requirements of high etch rate, surface smoothness, and good mask stability.

\section{Experimental}

The p-type (100)Si samples were boron-doped with a resistivity of 8 to $12 \Omega \mathrm{cm}$. Prior to each experiment the samples were standard RCA cleaned ${ }^{9}$ and the native oxide layer was removed by a $10 \mathrm{~s} \operatorname{dip}$ in a $2 \mathrm{M} \mathrm{HF}$ solution followed by rinsing with deionized water. Samples used in electrochemical experiments were provided with an ohmic contact $(\mathrm{Ga} / \mathrm{In}$ eutectic) on the back side. The samples were mounted with an O-ring in a Teflon holder exposing $0.5 \mathrm{~cm}^{2}$ to the solution. All experiments were performed at $70^{\circ} \mathrm{C}$. The chemicals used were of $\mathrm{p}$. a. grade (Merck).

Electrochemical experiments were performed in the dark using a Bank POS73 Potentioscan. The thermostatically controlled cell contained a working electrode whose surface faced upward, a Pt counterelectrode, and a saturated calomel electrode (SCE) as reference. All potentials are quoted with respect to SCE. The etch rate was determined by measuring the etched depth as a function of etching time using a Tencor Alpha-Step 500 surface pro- 
filer. A Cambridge CAMSCAN scanning electron microscope (SEM) was used to study the surface morphology of etched samples.

Wagon wheel shaped mask patterns $\left(\mathrm{Si}_{3} \mathrm{~N}_{4}\right)$, similar to those used by Seidel et al., ${ }^{2}$ were used to study the anisotropy of the etching process. The mask, with a diameter of $5 \mathrm{~cm}$, revealed 360 openings each $40 \mu \mathrm{m}$ broad with a $1^{\circ}$ angular separation. The openings cause an overlap, with a diameter of approximately $0.63 \mathrm{~cm}$, at the center of the pattern. Upon etching, a "cloverleaf" figure is obtained whose shape depends on the anisotropy. ${ }^{2}$ After the wafer was rinsed with water, the $\mathrm{Si}_{3} \mathrm{~N}_{4}$ mask was removed with concentrated HF to obtain a better view of the figure and to allow surface profile measurements.

\section{Results}

Alkaline solutions.-The current-potential characteristics of p-type (100)Si in $4.0 \mathrm{M} \mathrm{KOH}$ solution at $70^{\circ} \mathrm{C}$ in the dark are shown in Fig. 1. The curve was measured with a scan rate of $10 \mathrm{mV} \mathrm{s}^{-1}$ starting at $-2.0 \mathrm{~V}$. The shape of the curve is similar to that reported by others. ${ }^{10,11}$ The current-potential characteristics were discussed in a previous paper. ${ }^{12}$

The forward scan (from -2.0 to $0.0 \mathrm{~V}$ ) clearly shows three different potential regions. At potentials negative of the open-circuit value $\left(V_{\text {oc }}\right)$, which is at approximately $-1.0 \mathrm{~V}$, a low dark current is observed due to the reduction of water

$$
2 \mathrm{H}_{2} \mathrm{O}+2 e_{\mathrm{CB}}^{-} \rightarrow 2 \mathrm{OH}^{-}+\mathrm{H}_{2}
$$

Since this reduction involves electrons from the conduction band, the current in this region is less than $1 \mu \mathrm{A} \mathrm{cm} \mathrm{cm}^{-2}$. At potentials positive with respect to $V_{\text {oc }}$ an anodic current peak is observed, due to electrochemical oxidation of $\mathrm{Si}$. There is evidence to show that this reaction occurs via an activated intermediate of the chemical etching reaction. ${ }^{12}$ The decrease in current at potentials more positive than the peak potential $\left(V_{\mathrm{p}}\right)$ is due to the formation of a passivating oxide layer. The presence of the oxide explains the absence of the anodic current peak in the reverse scan (from 0.0 to $-2.0 \mathrm{~V}$ ).

Etch rate measurements of p-type (100)Si in $4.0 \mathrm{M} \mathrm{KOH}$ at $70^{\circ} \mathrm{C}$ as a function of the applied potential ${ }^{12}$ clearly show that, although silicon etching is mainly chemical, the potential can be important. At potentials negative with respect to $V_{\mathrm{p}}$ a potential-independent etch rate is observed (approximately $40 \mu \mathrm{m} / \mathrm{h}$ ). Visual inspection during these etching experiments revealed that gas evolution occurs in this potential range. At more positive potentials the etch

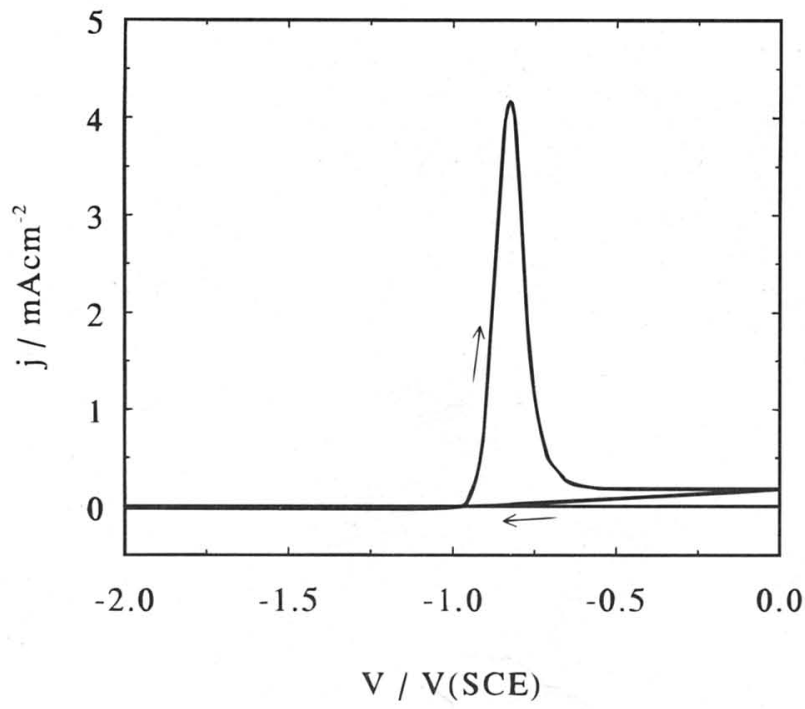

Fig. 1. Current-potential curve of p-type (100)Si in $4.0 \mathrm{M} \mathrm{KOH}$ at $70^{\circ} \mathrm{C}$. The scan was from -2.0 to $0.0 \mathrm{~V}$ and back to $-2.0 \mathrm{~V}$ at a rate of $10 \mathrm{mV} \mathrm{s}^{-1}$. The arrows indicate the scan direction. rate drops to a very low value due to the formation of the passivating oxide layer.

Figure 2 shows a surface profile of a p-type Si sample etched for half an hour at $V_{\text {oc }}$ in $4.0 \mathrm{M} \mathrm{KOH}$ at $70^{\circ} \mathrm{C}$ using an O-ring mask. The difference in scale of the $x$ - axis $(\mathrm{mm})$ and $z$-axis $(\mu \mathrm{m})$ should be noted. The profile shows that the area exposed to the solution is etched $20 \mu \mathrm{m}$ deep, corresponding to an etch rate of $40 \mu \mathrm{m} / \mathrm{h}$, while the bottom of the pit shows roughness of the order of a few microns. It is striking that reproducible, smooth areas were observed near the edges of the etched profile (Fig. 2). SEM pictures (Fig. 3) reveal that the roughness is caused by pyramidal hillocks. Figure $3 \mathrm{a}$ shows a top view of the surface and Fig. 3b was made under an angle of $30^{\circ}$ with respect to the surface.

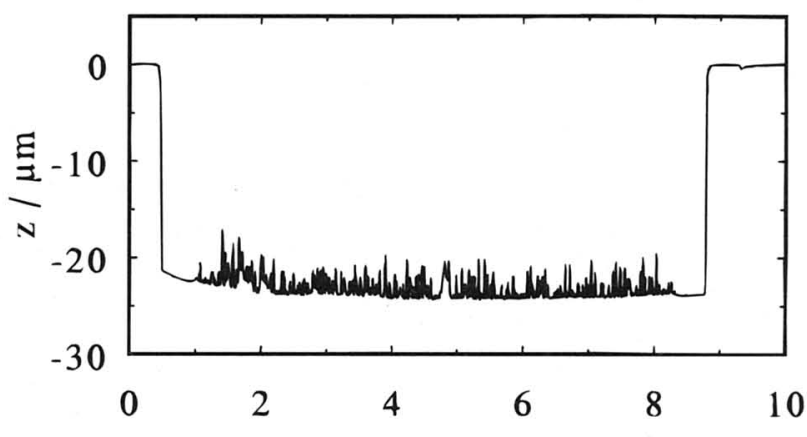

\section{$\mathrm{x} / \mathrm{mm}$}

Fig. 2. Surface profile of a p-type (100) sample etched $30 \mathrm{~min}$ at $V_{\text {oc }}$ in $4.0 \mathrm{M} \mathrm{KOH}$ at $70^{\circ} \mathrm{C}$.
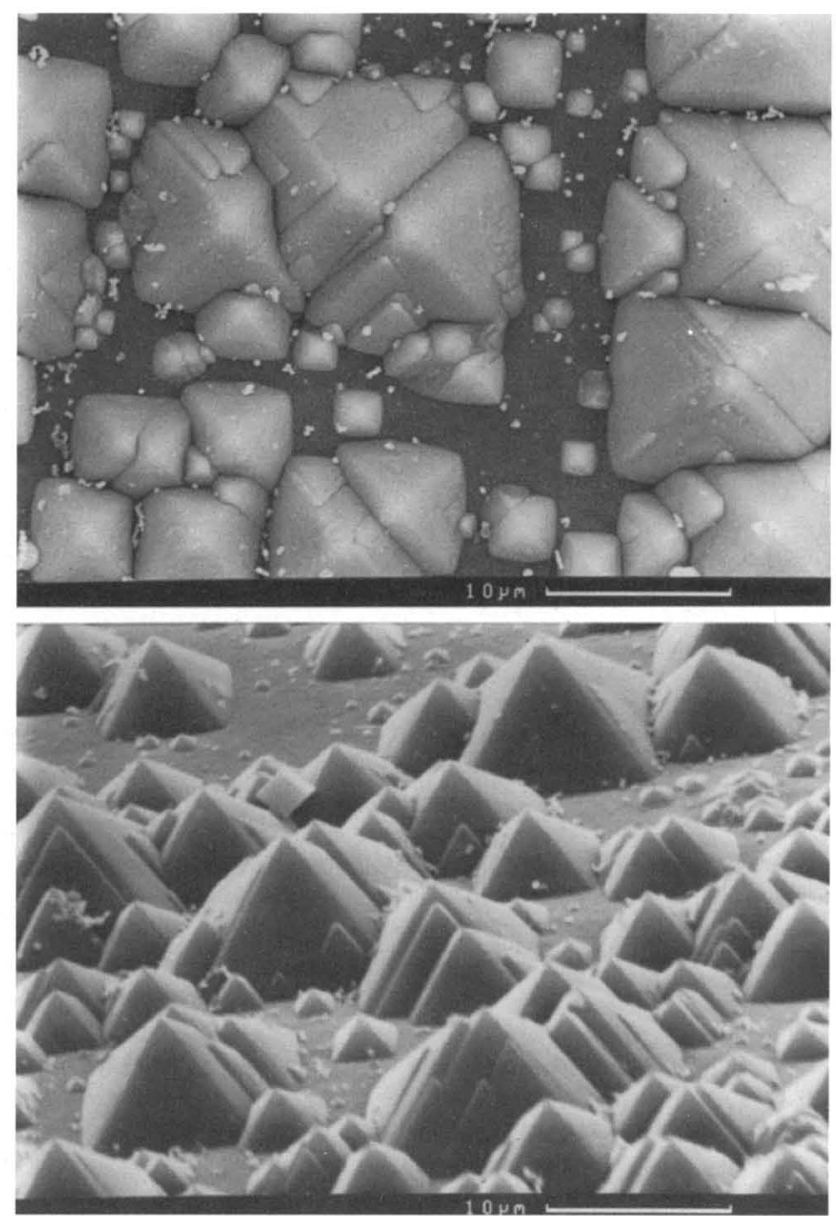

Fig. 3. SEM micrographs of a p-type (100) sample etched $30 \mathrm{~min}$ at $V_{\text {oc }}$ in $4.0 \mathrm{M} \mathrm{KOH}$ at $70^{\circ} \mathrm{C}$. (a) Top view and (b) under a $30^{\circ}$ angle with the (100) surface. 
The crystallographically oriented pyramids have dimensions of up to a few microns.

No effect of applied potential was observed on the surface roughness for samples etched at potentials negative with respect to $V_{\text {oc. }}$. Therefore, it was surprising that samples etched at potentials in the current peak became visibly smoother with increasing potential. The surface profile of a p-type (100) electrode etched for half an hour at $-0.85 \mathrm{~V}$ (near the peak maximum) showed that, while the etch rate was the same as that of the sample etched at $V_{\text {oc }}$, the surface was much smoother. To the eye, this sample looked mirror-like, similar to polished unetched Si. Figure 4 shows SEM pictures of samples etched at potentials in the anodic current peak (Fig. $4 \mathrm{a}$ ) at $-0.9 \mathrm{~V}$ and (Fig. $4 \mathrm{~b}$ ) at $-0.85 \mathrm{~V}$. A clear difference is observed with respect to the SEM micrographs of the sample etched at $V_{\text {oc }}$ (Fig. 3). The sample etched at $-0.9 \mathrm{~V}$ shows a much lower hillock density while the sample etched at $V_{\mathrm{p}}(-0.85 \mathrm{~V})$ shows no pyramidal structures. Pyramids were also not observed when a sample, previously etched at $V_{\text {oc }}$ (similar to Fig. 3), was re-etched at $-0.85 \mathrm{~V}$.

These results suggest that anodic oxidation is responsible for the decrease of hillock formation during etching. As a previous study ${ }^{12}$ revealed similarities between the electrochemical oxidation of silicon in the anodic current peak and the oxidation of silicon by potassium ferricyanide, we investigated the surface morphology of $\mathrm{Si}$ etched in solutions containing ferricyanide.

Alkaline solutions containing an oxidizing agent.-A detailed study of the reduction of ferricyanide at $\mathrm{p}$-type (100)Si and (111)Si in aqueous alkaline solutions is given in a previous work. ${ }^{12}$ At potentials negative of $V_{o c}$ a reduc-
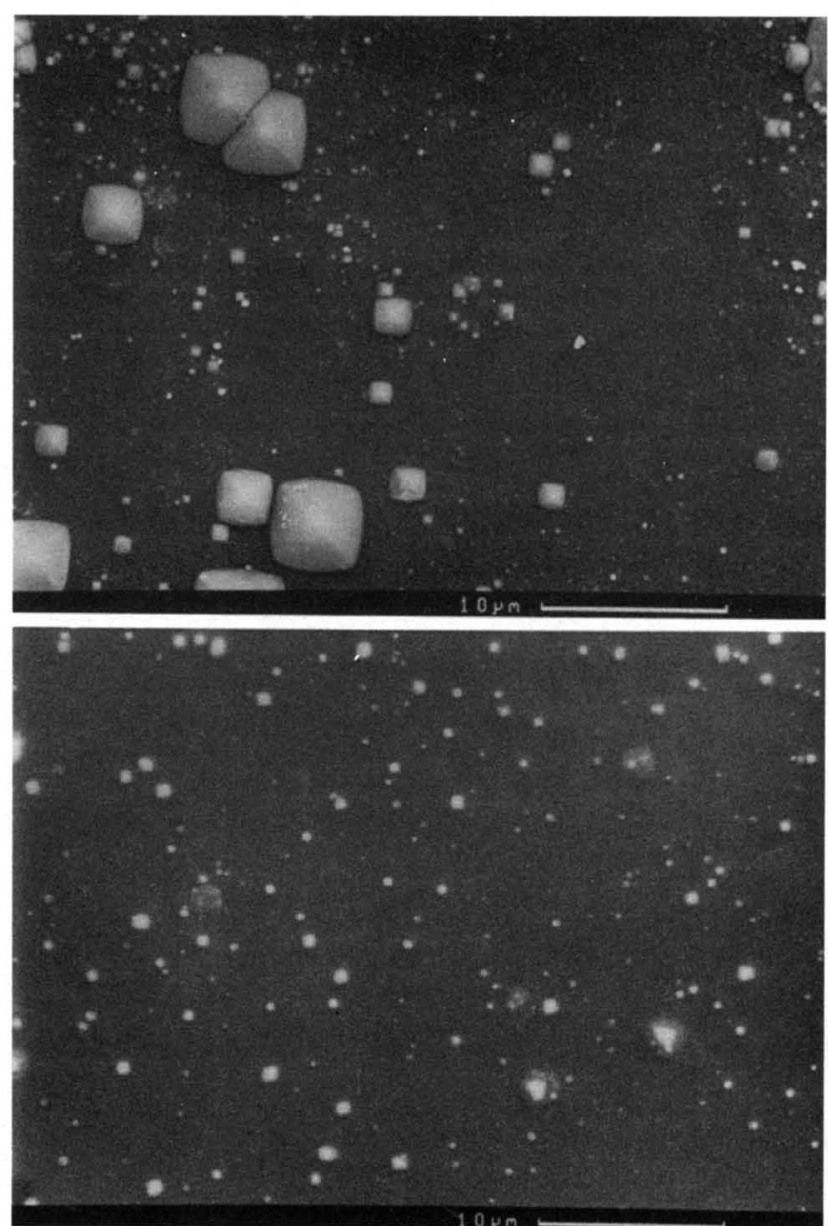

Fig. 4. Top view SEM pictures of p-type (100)Si etched $30 \mathrm{~min}$ in $4.0 \mathrm{M} \mathrm{KOH}$ at $70^{\circ} \mathrm{C}$. (a, top) at -0.9 and (b, bottom) at $-0.85 \mathrm{~V}$. tion current indicates that ferricyanide is reduced via hole injection into the valence band, as on many other semiconductors $^{13}$

$$
\mathrm{Fe}(\mathrm{CN})_{6}^{3-} \rightarrow \mathrm{Fe}(\mathrm{CN})_{6}^{4-}+h_{\mathrm{VB}}^{+}
$$

Electrochemical experiments in combination with etch rate measurements revealed that, at oxide-free chemically etching electrodes, part of the ferricyanide is reduced via an intermediate of the Si chemical etching process. This process shows similarities to the electrochemical etching in the anodic current peak which also seems to occur via an etch intermediate.

The etch rate was found to increase slightly (by less than $10 \%$ ) upon addition of ferricyanide to the solution. However, above a critical concentration of $35 \mathrm{mM}$ no etching was observed and the surface became hydrophilic, indicating the presence of an oxide layer. A marked effect on the surface roughness was observed at ferricyanide concentrations below the critical value. While surfaces etched in the solution without ferricyanide were rough, those etched in solutions containing the oxidizing agent became smoother with increasing concentration. SEM micrographs (Fig. 5) clearly show that the density of pyramids decreases with increasing ferricyanide concentration. This result is similar to that obtained at potentials in the anodic current peak. In both cases, pyramid formation is suppressed without a significant change of the etch rate. Moreover, oxide formation and passivation occur above a critical anodic current density and above a critical oxidizing agent concentration.

Wagon wheel masked samples were used to check if the reduction in hillock formation upon addition of ferricyanide is accompanied by a marked change in the anisotropy. Figure 6 shows a SEM micrograph of a p-type
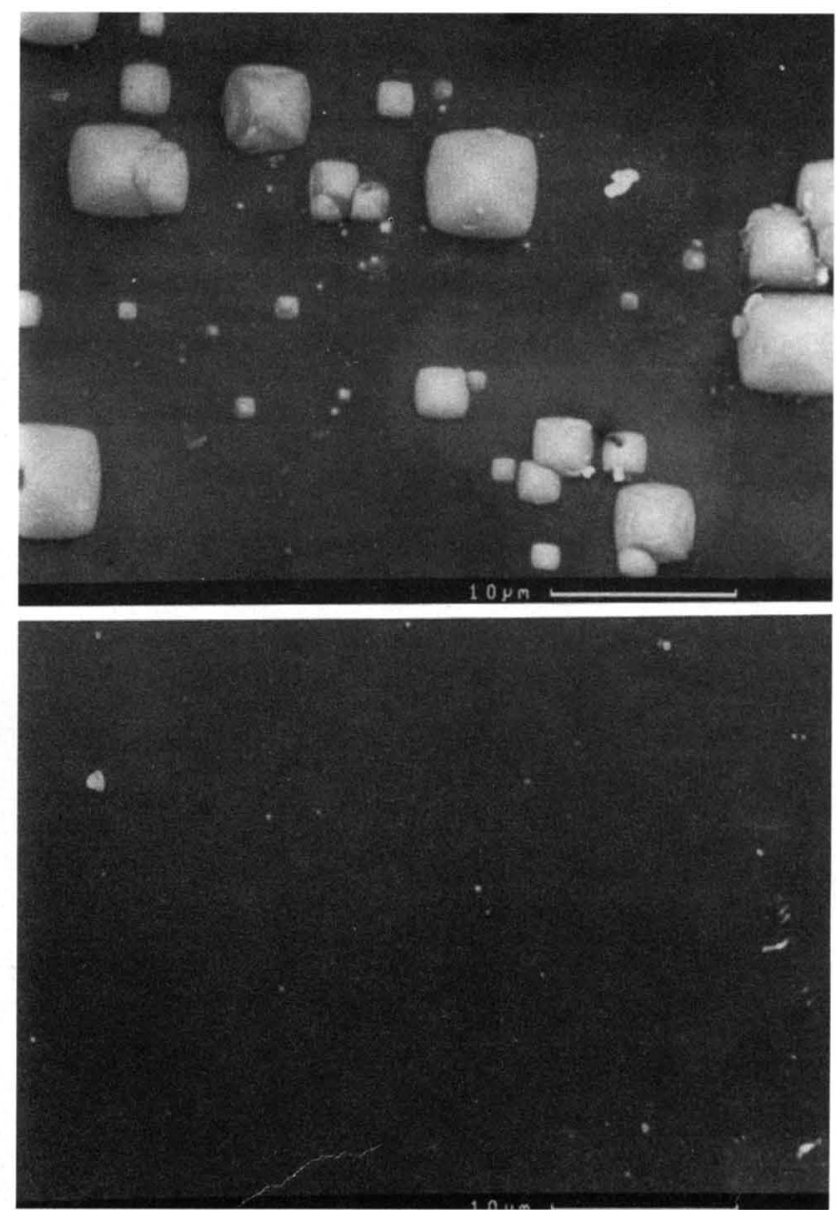

Fig. 5. SEM micrographs of p-type (100) samples etched $30 \mathrm{~min}$ at $70^{\circ} \mathrm{C}$ in $4.0 \mathrm{M} \mathrm{KOH}$ containing (a, top) $6 \mathrm{mM}$ and (b, bottom) $18 \mathrm{mM} \mathrm{K} \mathrm{Ke}_{3}(\mathrm{CN})_{6}$. 


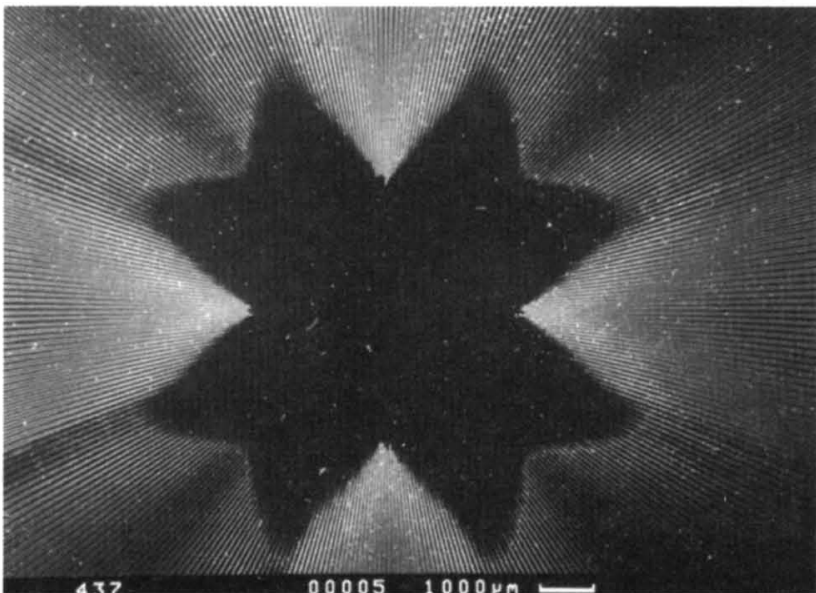

Fig. 6. Photograph of a wagon wheel masked p-type (100) sample etched at $V_{o c}$ for $15 \mathrm{~min}$ in $4.0 \mathrm{M} \mathrm{KOH}$ at $70^{\circ} \mathrm{C}$. An identical blossom-like figure was obtained when a solution containing 1.5 $\mathrm{mM} \mathrm{K} \mathrm{K}_{3} \mathrm{Fe}(\mathrm{CN})_{6}$ was used.

(100) sample etched for $15 \mathrm{~min}$ at $V_{\text {oc }}$ in $4.0 \mathrm{M} \mathrm{KOH}$ at $70^{\circ} \mathrm{C}$. Similar results were reported by Seidel et al. ${ }^{2}$ They determined the crystallographic orientation of the underetched sidewalls and found that only a limited number of crystal planes could be identified. The shape of the figure is due to total underetching of the mask in the vicinity of the center, leaving an area of bare exposed material. The radial extension depends on the etch rate of the crystallographic orientation of the individual segments, large for fast etching and small for the slow etching planes. The radial distances observed in Fig. 6 for the four minima is not due to total underetching (which is at these grooves negligible) but to an overlap of the grooves in the center of the pattern, as discussed before. This unmasked area is visibly rough like normal samples etched at $V_{\text {oc }}$. Similar masked samples were used for etching in solutions containing the oxidizing agent. Surprisingly, no etching occurred when a ferricyanide concentration of $5 \mathrm{~m} M$ was used. However, when the concentration was lowered to $1.5 \mathrm{mM}$ a clover-shaped structure was obtained with exactly the same radial distance ratio between the maxi$\mathrm{ma}$ and the relative minima observed in Fig. 6 . Although it is clear that ferricyanide does not drastically change the anisotropy of the system, one should realize that these samples are not appropriate for measuring the etch rate of the extremely slow etching (111) planes. Using $1.5 \mathrm{~m} M$ ferricyanide the surface of the figure was mirror-like as for an unmasked wafer etched in a solution containing $18 \mathrm{mM}$ ferricyanide. The observed difference in concentration dependence seemed to arise from the difference in active etching area, large in the case of unmasked and small in the case of the wagon wheel samples (the grooves were only $40 \mu \mathrm{m}$ broad).

To study this size effect, etching experiments were performed on p-type (100) samples provided with an oxide mask exposing an array of eight different square windows ranging from $5 \times 5$ to $1000 \times 1000 \mu \mathrm{m}$. Surface profile measurements of samples etched at $70^{\circ} \mathrm{C}$ in ferricyanidefree 4.0 $M \mathrm{KOH}$ solutions revealed that, while windows larger than $100 \times 100 \mu \mathrm{m}$ were etched at the same rate, smaller windows did not etch at all. Microscopic examination of the etched windows showed that the surface became smoother with decreasing size. Argon bubbling through the solution revealed that this passivation is due to the presence of another oxidizing agent, oxygen. Upon lowering the oxygen content in solution, the passivation threshold was lowered to windows smaller than $25 \times 25 \mu \mathrm{m}$. At the lowest oxygen concentrations even the smallest areas were etched; SEM examination of these samples revealed an extremely high surface coverage by hillocks, independent of the window size (Fig.7).

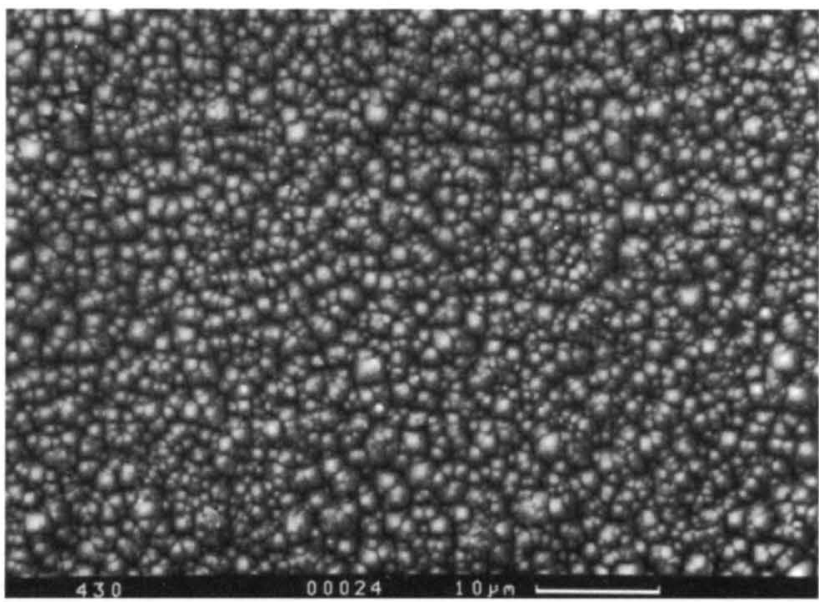

Fig. 7. SEM micrograph of a p-type (100) sample etched at $V_{o c}$ in an oxygen-free $4.0 \mathrm{M} \mathrm{KOH}$ solution at $70^{\circ} \mathrm{C}$.

\section{Discussion}

From previous work it was clear that (100)Si wafers are etched at a high rate in aqueous $4 \mathrm{M} \mathrm{KOH}$ solutions at $70^{\circ} \mathrm{C}$. However, etching is accompanied by the formation of a high density of pyramidal hillocks. In the present work we have shown that pyramid formation can be suppressed with retention of the etch rate either by fixing the potential of the Si at a value in the anodic current peak or by adding to the etchant an oxidizing agent such as ferricyanide. In addition, it is clear that if the potential applied during etching is made too positive (more positive than $V_{\mathrm{p}}$ ), or if the concentration of the oxidizing agent exceeds a critical value, then the $\mathrm{Si}$ passivates and etching ceases. We discuss these two effects in terms of a model we proposed on the basis of an electrochemical study of Si under etching conditions. ${ }^{12}$

A model for etching and passivation.-A simplified version of the model is shown in Fig. 8. For simplicity only one $\mathrm{Si}-\mathrm{Si}$ back bond and one $\mathrm{Si}-\mathrm{H}$ surface bond are taken into account. A more detailed discussion of this reaction scheme and of chemical etching is given elsewhere..$^{12}$ It is clear that Si etching in aqueous alkaline solutions is mainly chemical $^{10,11}$ and that water is the active etching

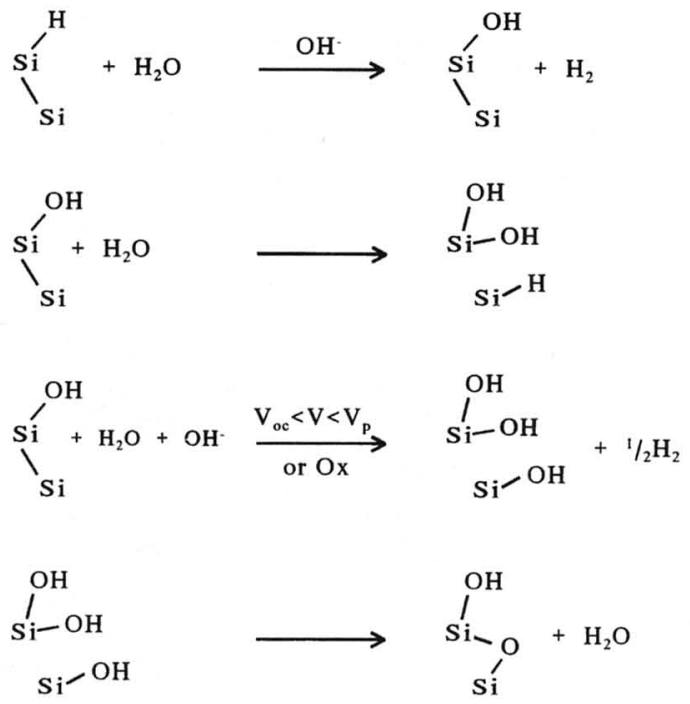

Fig. 8. Reaction scheme for the Si etching process. Step 2a represents the chemical attack of water on the Si back bond, while step $2 \mathrm{~b}$ occurs when either a potential is applied in the anodic current peak or in the presence of an oxidizing agent (ferricyanide). Step 3 implies the oxide formation from the neighboring $\mathrm{Si}-\mathrm{OH}$ groups formed in step $2 b$. 
species. ${ }^{14,15}$ The first step of etching involves the hydroxide-catalyzed rupture of an $\mathrm{Si}-\mathrm{H}$ surface bond by water and the formation of an $\mathrm{Si}-\mathrm{OH}$ bond and hydrogen gas. Due to this substitution the back bond becomes polarized, making attack by water more favorable. Since the surface atom is now more positively charged than the second row atom, the $\mathrm{OH}$ group from water bonds preferentially to the surface atom while the underlying atom becomes hydride bonded (step 2a). As the remaining Si-Si bonds are broken, the surface atom goes into solution $\left[\mathrm{as} \mathrm{Si}(\mathrm{OH})_{4}\right.$ or an equivalent species] leaving the surface hydrogen-terminated. ${ }^{16}$ This simple mechanism shows that the surface remains hydrogen-terminated as long as the first step is rate limiting.

The effect of applied potential in the current peak $\left(V_{\mathrm{oc}}<V<V_{\mathrm{p}}\right.$ ) or the presence of a strong oxidizing agent (ferricyanide) in solution is shown in reaction $2 \mathrm{~b}$. While in purely chemical etching (step 2a) an Si-H bond is formed, the oxidation reactions produce $\mathrm{Si}-\mathrm{OH}$ bonds, which can give rise to a bridged oxygen structure, as shown in the third step. In this way, an oxide is formed on the $\mathrm{Si}^{12}$ If the initial rate of formation of the oxide exceeds the maximum rate of dissolution then the surface becomes passivated and etching ceases. It is clear that this will occur when either a critical current density or a critical concentration of oxidizing agent is exceeded. Van den Meerakker and Van der Straaten ${ }^{17}$ have reported an analogous passivation effect for $\mathrm{Si}$ etching in aqueous $\mathrm{NH}_{3}$ solutions $(\mathrm{pH} \approx 12)$ containing $\mathrm{H}_{2} \mathrm{O}_{2}$, above a critical $\mathrm{H}_{2} \mathrm{O}_{2}$ concentration.

The fact that a considerably lower $\mathrm{Fe}(\mathrm{CN})_{6}^{3-}$ concentration is necessary to allow etching in $40 \mu \mathrm{m}$ wide grooves indicates the importance of mass transport in the case of chemical oxidation. ${ }^{13}$ The experiments involving argon bubbling show that dissolved oxygen also acts as oxidizing agent in the same way as ferricyanide, leading to passivation if mass transport is favorable. The pronounced effects seen on reducing the active etching area are due to a much more effective supply of oxidizing agent by two- or three-dimensional diffusion as compared to linear diffusion in the case of a semi-infinite etching surface. Such an effect, termed the oxygen diffusion size effect, ${ }^{18}$ can play an important role in various etching and deposition processes.

Pyramid stability and formation.-To a first approximation the structures formed on (100)Si surfaces in alkaline solutions (see Fig. 3) appear as regular pentahydrons consisting of four lateral $\{111\}$ facets. The edges of the square base are parallel to the $\langle 110\rangle$ directions. The pyramid sizes are not uniform indicating that hillocks are created and removed continuously during etching. ${ }^{6}$ The surprising stability of these structures can be understood using an atomic model and simple ideas regarding etching anisotropy. Three related effects are considered to be important: the number and accessibility of the back bonds to the surface $\mathrm{Si}$ atom and the corresponding nature of the surface hydride. On an ideal (111)Si surface, all surface atoms are triply bonded to the underlying $\mathrm{Si}$ atoms and the surface is cov- ered by monohydride. This is considerably more "stable" than, for example, the unreconstructed (100) surface would be with two back bonds and a dihydride. ${ }^{19, a}$

The model of Fig. 9 shows a pyramid defined by four triangular $\{111\}$ facets on a square base with sides parallel to the $<110>$ directions; the surface of the substrate is, for simplicity, shown unreconstructed. The silicon atoms (gray) are tetrahedrally coordinated and the dangling bonds are saturated with hydrogen atoms (white). It is striking that, apart from the topmost atom which has two $\mathrm{Si}-\mathrm{H}$ bonds, all other surface atoms, including those on the edges of the pyramid, are only monohydride bonded. This can explain the relative stability of the structure. To remove an atom from the sidewalls of the pyramid, the relatively stable surface monohydride must be hydrolyzed (step 1) and three $\mathrm{Si}-\mathrm{Si}$ back bonds have to be broken (step 2). The model also shows that while the back bonds of the atoms on the $\{111\}$ facets face into the lattice, those at the edges are more exposed making them more accessible for bond rupture by the etchant. Sharp edges between the $\{111\}$ facets and the (100) surface are generally observed when V-shaped grooves are etched along the $<110\rangle$ directions in (100)Si in alkaline solutions. ${ }^{3}$

Reed and co-workers ${ }^{5}$ examined the structures obtained in $\mathrm{KOH}$ solutions saturated with 2-propanol in detail and concluded that each facet is, in fact, composed of two $\{567\}$ planes which are slightly off the $<111>$ orientation. They showed that hillock elimination involves preferential attack along the four sharp <067> edges producing an extremely rough surface. The other large angle $\langle 7 \quad 7 \quad 11>$ edges, defining the hillock are not attacked, and the $\{567\}$ faces are relatively stable in the etchant.

Various suggestions have been made to explain the origin of pyramid formation during etching. Bhatnagar and Nathan $^{6}$ suggest that pyramids grow from structural defects in the wafer but their claim is not substantiated. In the work of Abbott et al. ${ }^{20}$ pyramid formation is linked to hydrogen diffusion into the semiconductor. They also observed smooth surfaces on etching in the presence of oxygen, but attributed this effect to a reaction of oxygen with (atomic) hydrogen, thereby reducing hydrogen absorption by the solid. Our results, however, show that smooth surfaces are obtained under applied potential despite the fact that hydrogen is evolved at a significant rate during etching; the rate of chemical etching which involves hydrogen evolution is considerably higher than the rate of the electrochemical reaction.

Tan et al. ${ }^{4}$ proposed a regrowth mechanism, suggesting that the etching reaction

${ }^{a}$ In order to account for the stability of the $<111>$ face one has to consider that this face has a double-layered structure (with a roughening temperature $>0) .{ }^{19}$ Taking both layers into account, the $<111>$ face has a honeycomb structure, with three bonds per atom to the three nearest neighbors in the layer. Every second atom has a bond pointing out of the crystal; this bond is hydrogen terminated. The other atoms have one bond that connects the layer to the bulk of the crystal. The latter atoms lie somewhat below, the former above the plane. In Fig. 9 only the former are visible.
Fig. 9. Atomic model of a pyramid made of four $\{111\}$ facets with sides along the $<110>$ directions on a (100)Si surface: (a) top view and (b) side view. All Si atoms (gray balls) have tetrahedral configuration. The bonds are saturated with hydrogen atoms (white balls).
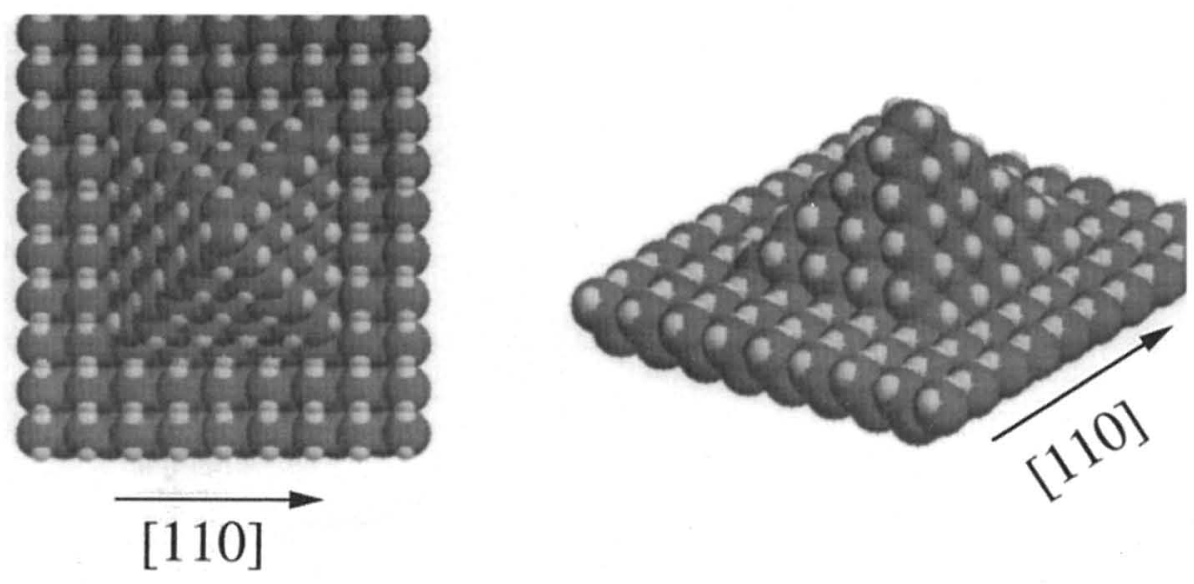


$$
\mathrm{Si}+2 \mathrm{OH}^{-}+2 \mathrm{H}_{2} \mathrm{O} \Leftrightarrow \mathrm{SiO}_{2}(\mathrm{OH})_{2}^{2-}+2 \mathrm{H}_{2}
$$

may, under certain conditions, be reversible, e.g., when etching products are not efficiently removed from the $\mathrm{Si}$ surface. However, while epitaxial growth would be expected to give pyramidal structures, ${ }^{21}$ thermodynamic $\mathrm{data}^{22}$ show that deposition of Si via such reactions is not possible.

Pyramid formation is also attributed to anisotropic underetching of spontaneously formed masks on the etching surface. Palik et al. ${ }^{23}$ suggested that hydrogen bubbles adhering to the surface can act as a local mask. In this case, however, hillocks with a circular base are observed, ${ }^{4}$ as has also been found in $\mathrm{GaAs}$ etching. ${ }^{24}$ These are obviously different from the pyramids of Fig. 3. It has been suggested ${ }^{25}$ that oxide, formed on the surface during etching, might provide temporary local masking to initiate pyramid formation. However, Sandmaier and co-workers ${ }^{26}$ show that convex edges of slow etching planes, such as those in pyramids, can only be obtained when very complex masking patterns are used; otherwise fast etching planes are revealed. ${ }^{3,26}$ It is extremely unlikely that an amorphous oxide would be deposited in such a crystallographically well-defined form to serve as such a mask. In addition, all our experiments show that conditions favoring oxidation and oxide formation lead to a reduction in surface roughness. We, therefore, conclude that the pyramids cannot be due to anisotropic underetching of spontaneously formed masks.

The model in Fig. 9, however, shows that once a small pyramid is formed, it can act as a self-propagating mask for further development of the pyramidal structure. The smallest pyramid necessary could consist of just seven silicon atoms. Such structures might be present in the intrinsic roughness of the (100) surface, which is known to have details up to $\mathrm{nm}$ dimensions. ${ }^{27,28}$ Alternatively, a limited growth of Si via a mechanism based on silane could be responsible. It is known that $\mathrm{SiH}_{4}$ can be formed during reaction of $\mathrm{Si}$ with water. ${ }^{29}$ While silane is not expected to be stable in strongly alkaline solutions, a limited deposition might give rise to a "pyramidal nucleus."

Pyramid suppression.-In the present work we have demonstrated that smooth surfaces can be obtained in two quite different ways: by etching under applied potential or by using a suitable oxidizing agent in solution. Nakamura et al., ${ }^{30}$ in etching experiments with $\mathrm{p}-\mathrm{n}$ junctions, also showed that smooth surfaces can be obtained with applied potential. If the mass transport conditions are favorable, oxygen can, like ferricyanide, prevent hillock formation; this is clear from the experiments involving the etching of small area windows. Abbott and co-workers ${ }^{20}$ have encountered a similar effect in experiments at atmospheric and high oxygen pressures. We believe that the much reduced roughness at the profile edges in Fig. 2 is also due to the enhanced oxygen diffusion at the resist edge. The favorable effect of solution agitation reported by various workers ${ }^{2,423,25}$ may, in fact, be due to an increase in the oxygen concentration in the etchant solution and/or an enhanced transport of the gas to the etching surface. Schnakenberg and co-workers ${ }^{31}$ show that addition of small amounts of another oxidizing agent, $\mathrm{H}_{2} \mathrm{O}_{2}$, to aqueous $\mathrm{NH}_{3}$ solutions also suppresses the formation of etch hillocks.

In the section on Pyramid stability and formation, we discussed the pyramid stability using an atomic model of pyramids consisting of four stable $\{111\}$ facets. As the back bonds at the edges of these planes are more exposed to the etchant, it is likely that chemical attack on the pyramids will start at the edges. Alternatively, attack at the edge may be initiated by removel of the top Si atom. Once a Si atom is removed, further attack along the edges can occur and could cause a roughening of the edges. Since, however, the pyramids retain their shape during etching it is more likely that removal of edge atoms gives rise to a step. It is known that etching of (111)Si surfaces occurs via steps. ${ }^{3 z, 33}$ As the steps propagate over the $\{111\}$ facets, the pyramid is "peeled." For pyramids to "survive," the etch rate of the (100) substrate should be larger than the "peel" rate of the $\{111\}$ facets. The fact that the pyramid sizes are small compared to the total etch depth (see for example Fig. 3), indicates that the ratio of the etch rate of the (100)Si surface to the "peel" rate of the facets is not much larger than 1.

It is interesting to note that Neuwald et al. ${ }^{28}$ report indirect STM evidence for pyramid formation on (100)Si surfaces etched in concentrated $\mathrm{NH}_{4} \mathrm{~F}$ solutions ( $\mathrm{pH}$ 8). The pyramids grow to a maximum height of $6 \mathrm{~nm}$ and reach a density of $10^{12} \mathrm{~cm}^{-2}$. To explain the constant average size of the pyramids, two mechanisms were suggested: a dynamic equilibrium involving continuous generation and removal of pyramids and a mechanism in which the vertical etch rate of the pyramids is equal to that of surrounding (100) terraces. The latter is similar to the approach suggested in this work.

According to our model (Fig. 8) the main effect of anodic polarization or of added oxidizing agent is to promote the formation of adjacent $\mathrm{Si}-\mathrm{OH}$ groups when the $\mathrm{Si}-\mathrm{Si}$ back bonds are ruptured by water; otherwise, an $\mathrm{Si}$ $\mathrm{OH} / \mathrm{Si}-\mathrm{H}$ combination is formed, yielding a hydrogen-terminated site. High $\mathrm{OH}^{-}$concentration and a corresponding low water activity is expected to have the same effect on the mechanism as the oxidizing agents. Two effects of etching under oxidizing conditions might be responsible for the suppression of pyramid formation. If silane decomposition were responsible for the formation of pyramidal structures, then obviously the reactant concentration under oxidizing conditions would be considerably reduced. Alternatively, one could envisage a somewhat faster attack on exposed Si-Si bonds at the pyramid edges during etching under oxidizing conditions. This might reverse the order of the etch and "peel" rates of the (100) surface and $\{111\}$ facets, respectively. In this case it is obvious that pyramids will be removed from the substrate.

\section{Conclusions}

A surface morphology study of p-type (100)Si etched in $4.0 \mathrm{M} \mathrm{KOH}$ solutions at $70^{\circ} \mathrm{C}$ reveals that etch-hillock formation can be suppressed in the presence of an oxidizing agent (ferricyanide or oxygen) or by etching at applied potential. In contrast to a currently used approach (etching at higher $\mathrm{KOH}$ concentration) these methods do not reduce the etch rate. Therefore, it is possible to etch smooth, mirror-like surfaces without the loss of etch rate or $\mathrm{SiO}_{2}$ mask stability. It is shown that, because of diffusion size effects, care should be taken when structures of different dimensions are etched simultaneously in solutions containing oxidizing agents. While etching under applied potential requires the presence of an ohmic contact, oxidizing agents can be used under open-circuit conditions. Addition of ferricyanide to the etchant seems most promising, as it is easy to control the concentration of this stable oxidizing agent. A ferricyanide-based etchant might, therefore, be an attractive alternative in Si micromachining for obtaining smooth hillock-free surfaces.

\section{Acknowledgments}

The authors wish to thank M. Plakman for help with the measurements. The work described here was supported by the Netherlands Foundation for Chemical Research (SON), with financial aid from the Netherlands Organization for Scientific Research (NWO).

Manuscript received Oct. 5, 1995.

Utrecht University assisted in meeting the publication costs of this article.

\section{REFERENCES}

1. D. L. Kendall, Appl. Phys. Lett., 26, 195 (1975).

2. H. Seidel, L. Csepregi, A. Heuberger and $H$. Baumgärtel, This Journal, 140, 3612 (1990).

3. K. E. Bean, IEEE Trans. Electron. Dev., ED-25, 1185 (1978). 
4. S. Tan, H. Han, R. Boudreau, and M. L. Reed, in Proceedings of the Workshop on Micro Electro Mechanical Systems, p. 229, Oiso, Japan (1994).

5. S. Tan, M. L. Reed, H. Han, and R. Boudreau, $J$. Micromech. Microeng. 4, 147 (1994).

6. Y. K. Bhatnagar and A. Nathan, Sens. Act. A, 36, 233 (1993).

7. T. A. Kwa, P. J. French, R. F. Wolffenbuttel, P. M. Sarro, L. Hellemans, and J. Snauwaert, This Journal, 142, $1226(1995)$

8. L. Ternez, Y. Bäcklund, J. Tiren, and J. O’Connell, Sens. Mater., 1-6, 313 (1989).

9. W. Kern and D. A. Puotinen, RCA Rev., 31, 187 (1970).

10. R. L. Smith, B. Kloeck, N. de Rooij, and S. D. Collins, $J$. Electroanal. Chem., 238, 103 (1987)

11. O. J. Glembocki, R. E. Stahlbush, and M. Tomkiewicz, This Journal, 132, 145 (1985).

12. P. M. M. C. Bressers, S. A. S. P. Pagano, and J. J. Kelly, $J$. Electroanal. Chem., 391, 159 (1995).

13. P. H. L. Notten, J. E. A. M. van den Meerakker, and J. J. Kelly, Etching of III-V Semiconductors; An Electrochemical Approach, Elsevier Advanced Technology, Oxford (1991).

14. P. Allongue, V. Costa-Kieling, and H. Gerischer, This Journal, 140, 1018 (1993).

15. S. A. Campbell, D. J. Schiffrin, and P .J. Tufton, $J$. Electroanal. Chem., 344, 211 (1993).

16. J. Rappich, H. J. Lewerenz, and H. Gerischer, This Journal, 140, L187 (1993).

17. J. E. A. M. van den Meerakker and M. H. M. van der Straaten, ibid., 137, 1239 (1990).

18. J. W. M. Jacobs and J. M. G. Rikken, ibid., 135, 2822 (1988).
19. See, e.g., P. Hartman, Z. Kristallogr., 121, 78 (1965) or P. Bennema and J. P. van der Eerden, in Morphology of Crystals, I. Sunagawa, Editor, Terrapub, Tokyo (1987).

20. A. P. Abbott, S. A. Campbell, J. Satherley, and D. J. Schiffrin, J.Electroanal. Chem., 348, 473 (1993).

21. J. G. E. Gardeniers, W. E. J. R. Maas, R. Z. C. van Meerten, and L. G. Gieling, J. Cryst. Growth, 96, 821 (1989).

22. A. J. Bard, R. Parsons, and J. Jordan, Standard Potentials in Aqueous Solution, Chap. 8, Marcel Dekker, Inc., New York (1985).

23. E. D. Palik, O. J. Glembocki, I. Heard, P.S. Burno, and L. Tenerz, J. Appl. Phys., 70, 3291 (1991).

24. J. Weyher and W. J. P. van Enckevort, J. Cryst. Growth, 63, $292(1983)$

25. U. Schnakenberg, W. Benecke, and B. Löchel, Sens. Act. A, 21-23, 1031 (1990).

26. H. L. Offereins, K. Kühl, and H. Sandmaier, ibid., 25-27, 9 (1991).

27. P. Dumas, Y. J. Chabal, and P. Jakob, Surf. Sci., 269/270, 867 (1992).

28. U. Neuwald, H. E. Hessel, A. Feltz, U. Memmert, and R. J. Behm, Surf. Sci., 296, L8 (1993).

29. I. Lampert, H. Fußstetter, and H. Jacob, This Journal 133, 1472 (1986)

30. M. Nakamura, K. Murakami, H. Nojiri, and T. Tominaga, Transducers '87, p. 112 (1987).

31. U. Schnakenberg, W. Benecke, B. Löchel, S. Ullerich, and P. Lange, Sens. Act. A, 25-27, 1 (1991)

32. P. Allongue, V. Costa-Kieling, and $\mathrm{H}$. Gerischer, This Journal, 140, 1009 (1993).

33. M. Elwenspoek, ibid., 140, 2075 (1993).

\title{
Etching of $6 \mathrm{H}-\mathrm{SiC}$ and $4 \mathrm{H}-\mathrm{SiC}$ using $\mathrm{NF}_{3}$ in a Reactive lon Etching System
}

\author{
J. B. Casady," E. D. Luckowski, M. Bozack, D. Sheridan, R. W. Johnson, and J. R. Williams \\ NASA Center for Commercial Development, Departments of Electrical Engineering and Physics, Auburn University, \\ Auburn, Alabama 36849-5201, USA
}

\section{ABSTRACT}

The use of pure $\mathrm{NF}_{3}$ source gas in reactive ion etching of bulk and epitaxy, Si-face, $6 \mathrm{H}-\mathrm{SiC}$, and $4 \mathrm{H}-\mathrm{SiC}$ is reported. The effects of $\mathrm{RF}$ power and chamber pressure on etch rate and surface morphology are discussed. A process developed for a smooth, residue-free etch, with a relatively high etch rate of $\sim 1500 \AA ̊ / \mathrm{min}$ is examined using scanning electron microscopy and Auger electron spectroscopy surface analysis. The process developed had a self-induced dc bias ranging from 25 to $50 \mathrm{~V}$, a forward RF power of $275 \mathrm{~W}\left(1.7 \mathrm{~W} / \mathrm{cm}^{2}\right)$, chamber pressure of $225 \mathrm{mT}$, and a $\mathrm{NF}_{3}$ flow rate between 95 and $110 \mathrm{sccm}$. No chemical residue or aluminum micromasking was observed on any of the samples etched with the above process.

\section{Introduction}

$\mathrm{SiC}$ devices have shown great promise for use in high power, high frequency, and high temperature applications. $^{1-3}$ A clean, fast, reproducible, and reliable etch process is essential for device fabrication in silicon carbide (SiC), which will have minimal effect upon the electrical properties of $\mathrm{SiC}$. The use of fluorinated gas chemistry $\left(\mathrm{NF}_{3}, \mathrm{SF}_{6}, \mathrm{CF}_{4}, \mathrm{XeF}_{2}, \mathrm{CHF}_{3}\right.$, etc.) in reactive ion etching (RIE) of SiC has been documented, ${ }^{4-13}$ but RIE processes still need refinement to obtain high etch rates, while leaving a smooth, clean surface which will not affect SiC device fabrication.

RIE is typically performed in a parallel plate or planar plasma etcher, with substrates placed upon the RF electrode, as opposed to the ground electrode, resulting in a higher electrode to plasma dc potential. Reactive ion etching is typically performed under low pressure $(\sim 10$ to $100 \mathrm{mT}$ ), which allows for very high ionic bombardment energy. Ionic bombardment of the surface can rupture bonds, as well as increase the probability of sputtering and

* Electrochemical Society Student Member. chemical interactions. Thus RIE is a process which is a mixture of reactive chemistry and mild sputtering by positive ions. ${ }^{14}$

RIE can also induce surface radiation damage. Radiation damage effects are generally reduced by lowering the selfbias voltage, thereby lowering the incident ion energy. However, the degree of anisotropy in the etch is compromised by lowering the incident ion energy. This trade-off is often of major concern. The surface damage caused by ionic and photonic bombardment in RIE affects numerous semiconductor device properties by changing the surface density of states $\left(N_{\mathrm{ss}}\right)$. Important field effect transistor (FET) device parameters such as small-signal transconductance $\left(g_{\mathrm{m}}\right)$, threshold voltage $\left(V_{\mathrm{TH}}\right)$, gate Schottky barrier height $\left(q \phi_{\mathrm{B}}\right)$, and ohmic contact resistance are all affected. Also, in metal oxide semiconductor field effect transistors (MOSFETs), RIE creates traps in gate oxides which affect the threshold voltage, and degrade the oxide quality. ${ }^{14}$

\section{RIE Etching of $6 \mathrm{H}-\mathrm{SiC}$ and $4 \mathrm{H}-\mathrm{SiC}$}

Here, RIE of $6 \mathrm{H}-\mathrm{SiC}$ and $4 \mathrm{H}-\mathrm{SiC}$ utilizing a source gas of pure $\mathrm{NF}_{3}$ is examined. Etch rates as a function of pres- 